\title{
Police Performance Rankings Depend on the Functional Form of the Index: A Comment on Bearfield, Maranto and Wolf
}

\author{
David S. Reed \\ Center for Public Administrators \\ David.Reed@PubAdmin.org
}

Bearfield, Maranto and Wolf (2020) advise policy-makers to measure policing outcomes using a metric that includes rates of homicide, police-related civilian deaths (PRCD) ${ }^{1}$, and poverty. They present such an index, which they call the Police Performance Index (PPI). But alternative functional forms that are equally plausible can lead to different rankings of police departments, and therefore different policy conclusions.

Bearfield, Maranto and Wolf's index is:

$$
\text { PPI }=10-\text { Ln ((Homicide Rate * PRCD Rate }) / \text { Poverty Rate })
$$

One alternative index of the same variables is:

$$
\text { Alternative Index }=\mathrm{Z}(\text { Homicide Rate })+\mathrm{Z}(\text { PRCD Rate })-\mathrm{Z}(\text { Poverty Rate })
$$

Where $\mathrm{Z}$ is the standardized value:

$$
\mathrm{Z}(\mathrm{x})=(\mathrm{x}-\mu) / \sigma
$$

The two indexes result in different rankings of the cities in Bearfield, Maranto and Wolf's data, as shown in Table 1.

\footnotetext{
${ }^{1}$ Bearfield, Maranto and Wolf abbreviate police-related civilian deaths as PRCD in most parts of their paper and PRDC in other parts. I abbreviate it as PRCD in this comment.
} 
TABLE 1

Ranking of Cities by Police Performance Index (PPI) and an Alternative Index

\begin{tabular}{lcc}
\hline City & Rank by PPI & Rank by Alternative Index \\
\hline New York City & 1 & 1 \\
El Paso & 2 & 2 \\
San Diego & 3 & 7 \\
Austin & 4 & 4 \\
San Jose & 5 & 10 \\
Charlotte-Mecklenburg & 6 & 6 \\
Los Angeles & 7 & 3 \\
Nashville-Davidson & 8 & 5 \\
San Francisco & 9 & 13 \\
Seattle & 10 & 15 \\
Fort Worth & 11 & 9 \\
Denver & 12 & 14 \\
San Antonio & 13 & 8 \\
Dallas & 14 & 12 \\
Houston & 15 & 11 \\
Phoenix & 16 & 18 \\
Columbus & 17 & 20 \\
Indianapolis & 18 & 16 \\
Chicago & 19 & 17 \\
Jacksonville & 20 & 22 \\
Philadelphia & 21 & 19 \\
Washington, D.C. & 22 & 23 \\
Detroit & 23 & 21 \\
\hline
\end{tabular}


Figure 1 shows the ranking of a hypothetical city that has the mean Homicide Rate and mean Poverty Rate from Bearfield, Maranto and Wolf's data, with its PRCD Rate varying from the lowest to the highest in their data. Changes in the city's PRCD Rate have a larger potential effect on its ranking under the Alternative Index than under PPI. For example, if the hypothetical city improves its PRCD Rate from 2 to 1.75 , there is no change in its ranking by PPI, but its ranking improves from 13th place to 8th place by the Alternative Index.

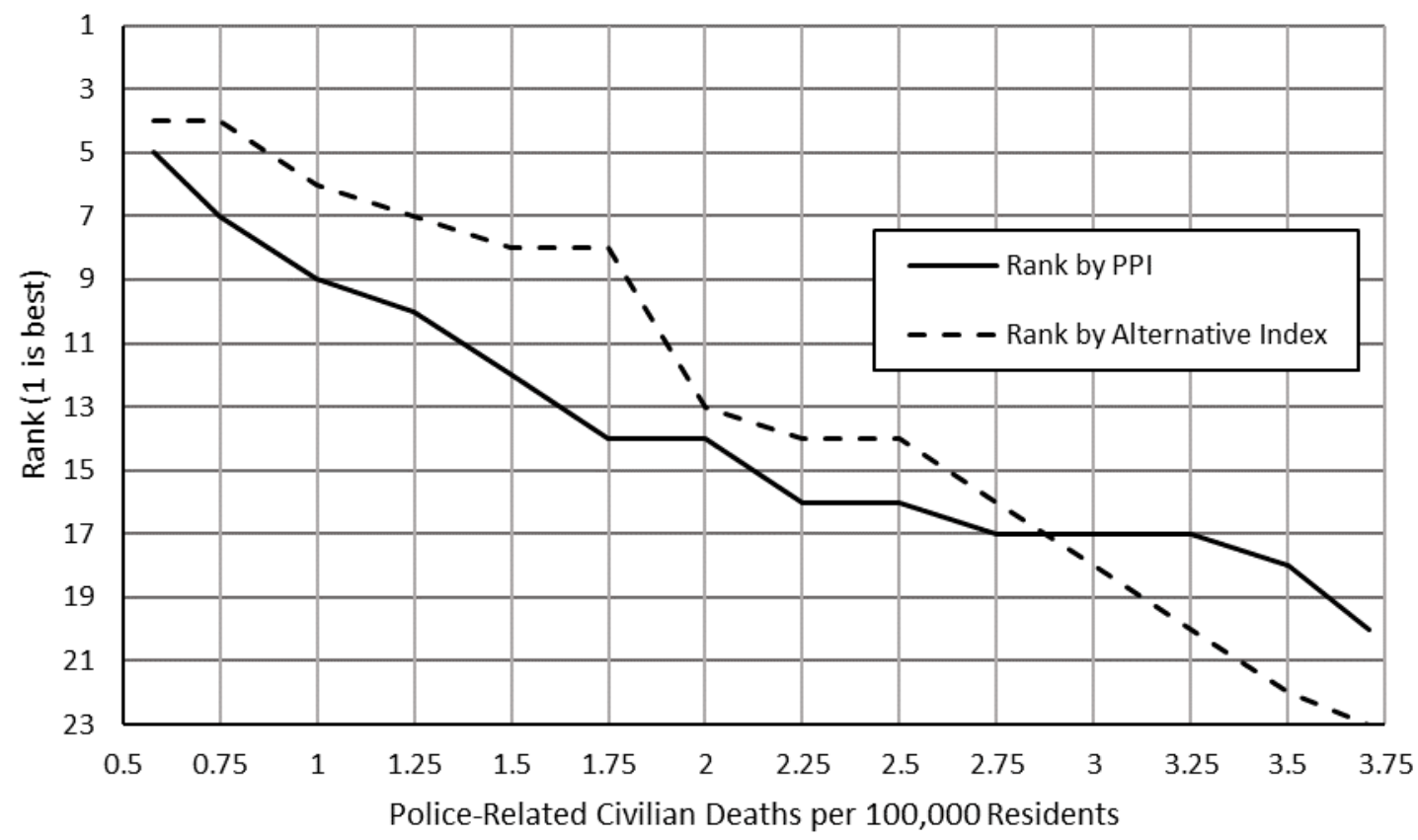

Figure 1. Rank on Police Performance Indexes, by Police-Related Civilian Deaths

Neither index is more correct than the other, because there is no measured dependent variable by which to validate them. The point is that the functional form chosen for an index has consequences for the resulting rankings.

Keywords: performance measurement; indexes; league tables; rankings; Police Performance Index

The data and computations used in this comment are available from the author.

\section{References}

Bearfield, D., Maranto, R., \& Wolf, P. J. (2020). Making Violence Transparent: Ranking Police Departments in Major U.S. Cities to Make Black Lives Matter. Public Integrity, O(0), 1-17. https://doi.org/10.1080/10999922.2020.1810601 